University of Nebraska - Lincoln

DigitalCommons@University of Nebraska - Lincoln

Michigan Bovine Tuberculosis Bibliography and

Database

Wildlife Disease and Zoonotics

1997

\title{
Bovine Tuberculosis in Free-Ranging White-Tailed Deer From Michigan
}

Stephen M. Schmitt

Scott D. Fitzgerald

Thomas M. Cooley

Colleen S. Bruning-Fann

Larry SullIvan

See next page for additional authors

Follow this and additional works at: https://digitalcommons.unl.edu/michbovinetb

Part of the Veterinary Medicine Commons

Schmitt, Stephen M.; Fitzgerald, Scott D.; Cooley, Thomas M.; Bruning-Fann, Colleen S.; SullIvan, Larry; Berry, Dale; Carlson, Thomas; Minnis, Richard B.; Payeur, Janet B.; and Sikarskie, James, "Bovine Tuberculosis in Free-Ranging White-Tailed Deer From Michigan" (1997). Michigan Bovine Tuberculosis Bibliography and Database. 99.

https://digitalcommons.unl.edu/michbovinetb/99

This Article is brought to you for free and open access by the Wildlife Disease and Zoonotics at DigitalCommons@University of Nebraska - Lincoln. It has been accepted for inclusion in Michigan Bovine Tuberculosis Bibliography and Database by an authorized administrator of DigitalCommons@University of Nebraska Lincoln. 


\section{Authors}

Stephen M. Schmitt, Scott D. Fitzgerald, Thomas M. Cooley, Colleen S. Bruning-Fann, Larry Sulllvan, Dale Berry, Thomas Carlson, Richard B. Minnis, Janet B. Payeur, and James Sikarskie 


\title{
BOVINE TUBERCULOSIS IN FREE-RANGING WHITE-TAILED DEER FROM MICHIGAN
}

\author{
Stephen M. Schmitt, ${ }^{1}$ Scott D. Fitzgerald, ${ }^{2}$ Thomas M. Cooley, Colleen S. Bruning-Fann, ${ }^{3}$ \\ Larry Sullivan, ${ }^{4}$ Dale Berry, ${ }^{5}$ Thomas Carlson, ${ }^{6}$ Richard B. Minnis, ${ }^{7}$ Janet B. Payeur, ${ }^{8}$ and \\ James Sikarskie ${ }^{9}$ \\ ' Wildlife Disease Laboratory, Rose Lake Wildlife Research Station, Michigan Department of Natural Resources, \\ East Lansing, Michigan 48823, USA \\ ${ }^{2}$ Animal Health Diagnostic Laboratory and Department of Pathology, College of Veterinary Medicine, \\ Michigan State University, East Lansing, Michigan 48824, USA \\ ${ }^{3}$ Animal and Plant Health Inspection Service, Veterinary Services, United States Department of Agriculture, \\ Holt, Michigan 48842, USA \\ 4 Animal Industry Division, Michigan Department of Agriculture, Lansing, Michigan 48909, USA \\ ${ }^{5}$ State Community Health Laboratory, Michigan Department of Community Health, Lansing, Michigan 48909, USA \\ ${ }^{6}$ Atlanta Field Office, Wildlife Division, Michigan Department of Natural Resources, Atlanta, Michigan 49709, USA \\ ' Department of Wildlife and Fisheries, Mississippi State University, Mississippi State, Mississippi 39762, USA \\ - National Veterinary Services Laboratories, United States Department of Agriculture, Ames, lowa 50010, USA \\ ${ }^{9}$ Small Animal Clinical Sciences, College of Veterinary Medicine, Michigan State University, East Lansing, \\ Michigan 48824, USA
}

ABSTRACT: A 4.5 yr-old male white-tailed deer (Odocoileus virginianus) killed by a hunter during the 1994 firearm hunting season in northeastern Michigan (USA) had lesions suggestive of tuberculosis and was positive on culture for Mycobacterium bovis the causative agent for bovine tuberculosis. Subsequently, a survey of 354 hunter-harvested white-tailed deer for tuberculosis was conducted in this area from 15 November 1995 through 5 January 1996. Heads and/or lungs from deer were examined grossly and microscopically for lesions suggestive of bovine tuberculosis. Gross lesions suggestive of tuberculosis were seen in 15 deer. Tissues from 16 deer had acid-fast bacilli on histological examination and in 12 cases mycobacterial isolates from lymph nodes and/or lungs were identified as $M$. bovis. In addition, lymph nodes from 12 deer ( 11 females and 1 male) without gross or microscopic lesions were pooled into 1 sample from which $M$. bovis was cultured. Although more male (9) than female (3) deer had bovine tuberculosis infections, this difference was not statistically significant. Mycobacterium bovis culture positive deer ranged in age from 1.5 to $5.5 \mathrm{yr}$ with a mean of $2.7 \mathrm{yr}$ (median $2.5 \mathrm{yr}$ ) for males and $3.2 \mathrm{yr}$ (median 3.5 $\mathrm{yr}$ ) for females. This appears to be the first epidemic occurrence of $\boldsymbol{M}$. bovis in free-ranging cervids in North America. A combination of environmental (high deer density and poor quality habit) and management-related factors (extensive supplemental feeding) may be responsible for this epizootic.

Key words: Bovine tuberculosis, epidemic, Mycobacterium bovis, Odocoileus virginianus, pathology, white-tailed deer.

\section{INTRODUCTION}

There are few reported cases of bovine tuberculosis in free-ranging cervids in North America (Stumpff, 1982; Clifton-Hadley and Wilesmith, 1991; Essey and Vantiem, 1995; Rhyan et al., 1995). Bovine tuberculosis has been reported in four white-tailed deer (Odocoileus virginianus) from New York (Levine, 1934; Friend et al., 1963) and one from Ontario (Belli, 1962); three axis deer (Axis axis) from Hawaii (Sawa et al., 1974); one elk (Cervus elaphus) from Manitoba (Rhyan et al., 1992); one mule deer (Odocoileus hemionus) from Montana (Rhyan et al., 1995); and two mule deer, six moose (Al- ces alces), and 73 elk from Alberta (Hadwen, 1942). All cases, except the white-tailed deer from Ontario, were geographically associated with $M$. bovis infected cattle, bison, captive elk, or feral swine (Rhyan et al., 1995). Once the infected animals were removed, bovine tuberculosis was not maintained in the free-ranging cervid populations (Essey and Vantiem, 1995). Based on empirical evidence, it was commonly believed that without infected domestic livestock to transmit the disease to free-ranging cervids, there was little likelihood that $M$. bovis would be maintained in free-ranging cervid populations (Essey and Vantiem, 1995).

Approximately $50 \mathrm{yr}$ ago, Michigan led 


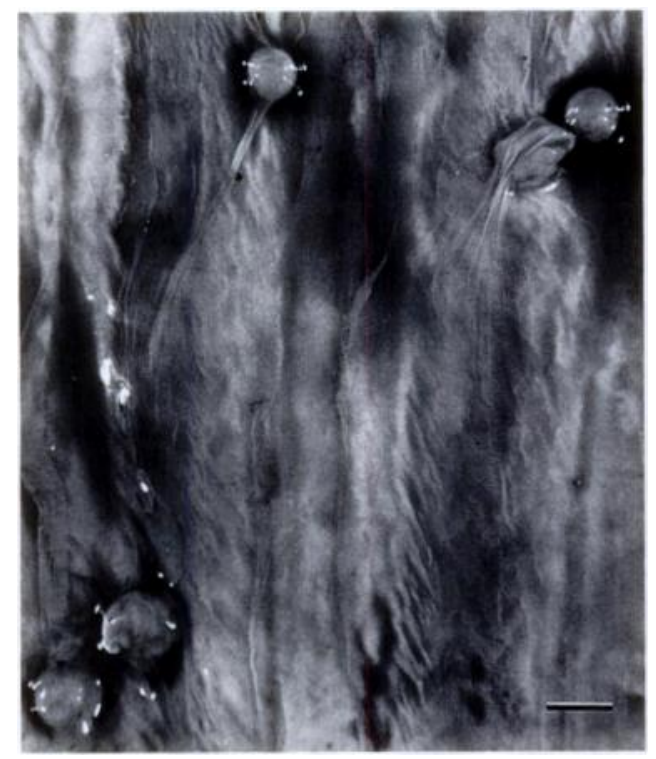

Figure 1. Rib cage from a white-tailed deer in Michigan infected with Mycobacterium bovis. Note the multiple $5 \mathrm{to} 10 \mathrm{~mm}$ diameter pale raised nodules on the parietal pleura. Bar $=1 \mathrm{~cm}$

the United States in the number of cattle testing positive for bovine tuberculosis with $30 \%$ of the national total (Frye, 1995). Implementation of the bovine tuberculosis eradication program resulted in Michigan becoming classified as bovine tuberculosis free in 1979. However, a hunter-killed 9.5-yr-old, female free-ranging white-tailed deer taken in Alcona County, Michigan in November 1975, had gross lesions suggestive of tuberculosis (numerous 3 to $15 \mathrm{~mm}$ nodules containing gritty or caseous material) throughout the pleura (Stuht and Fay, 1975). Histopathologic findings were compatible with tuberculosis (Keahey, 1976) and M. bovis was confirmed on culture (V. Mallmann, pers. commun.). Because the $1975 \mathrm{M}$. bovis positive deer was believed to be an isolated case, no further testing of the surrounding deer or livestock was performed.

In November 1994, a free-ranging 4.5yr-old male white-tailed deer was harvested during the firearm deer season on private land in the northeast portion of Michigan's lower peninsula (Alpena County, USA; $\left.44^{\circ} 52^{\prime} \mathrm{N}, 83^{\circ} 51^{\prime} \mathrm{W}\right)$. The bovine tuberculosis positive deer killed in 1975 was harvested approximately $13 \mathrm{~km}$ from where the bovine tuberculosis positive deer was harvested in 1994. The 1994 animal had thoracic lesions that included abscesses in the lungs and on the pleura (Fig. 1). The hunter contacted the Michigan Department of Natural Resources (MDNR) and provided the carcass for examination. The deer was examined at the MDNR Rose Lake Wildlife Disease Laboratory (East Lansing, Michigan, USA) and at the Animal Health Diagnostic Laboratory (AHDL) at Michigan State University (MSU; East Lansing, Michigan, USA) and a tentative diagnosis of bovine tuberculosis was made. Mycobacterium bovis was isolated from lung tissue by the Michigan Department of Community Health (MDCH; Lansing, Michigan, USA) and the National Veterinary Services Laboratories (NVSL), United States Department of Agriculture (USDA; Ames, Iowa, USA). This constituted the first reported occurrence of bovine tuberculosis in a free-ranging white-tailed deer in North America since 1961 (Friend et al., 1963).

Based on historical data, it was thought possible that the $1994 \mathrm{M}$. bovis infected deer was associated with tuberculous livestock. In spring 1995, personnel from the Michigan Department of Agriculture (MDA; Lansing, Michigan, USA) and the USDA tested all livestock (771 cattle, 14 swine and 17 goats) within a $16 \mathrm{~km}$ radius of the 1994 positive deer. No evidence of tuberculosis was found in the livestock. Also during the spring of 1995 , the MDNR collected 14 deer from an $8 \mathrm{~km}$ radius surrounding the area where the infected deer was killed in 1994. No evidence of $M$. bovis was found in these deer based on necropsies, histopathology and culture of cervical and thoracic lymph nodes. Deer from two captive herds within the boundaries of the surveillance area were examined by histopathology and culture whenever animals died or were culled. Twenty-three deer from these herds were examined; there was no evi- 
dence of bovine tuberculosis. In order to determine if $\boldsymbol{M}$. bovis existed in the freeranging deer population, a more extensive survey of hunter-killed deer within a 16 $\mathrm{km}$ radius of the 1994 positive deer was planned for the 1995 deer hunting season. Results of the survey, including gross and microscopic lesions, mycobacterial isolation results, and management plans are presented here.

\section{MATERIALS AND METHODS}

In November 1995, deer hunters were asked to cooperate in a survey to determine if bovine tuberculosis existed in the free-ranging deer population from which the tuberculous deer was harvested in 1994. In order to detect a disease present in a population at a low prevalence, a large sample size is required. A sample size of approximately 300 deer is sufficient to detect at least one tuberculous deer with 95\% confidence when the prevalence is $\geq 1 \%$ (Martin et al., 1987). During fall 1995, heads and/or lungs were requested from deer harvested by hunters from within a $16 \mathrm{~km}$ radius of the location where the tuberculous deer was harvested the previous hunting season. Any additional tuberculous deer would most likely be found in the usual range of the infected deer. Based on the MDNR estimate that white-tailed deer in this area range up to $8 \mathrm{~km}$, a sample area of $16 \mathrm{~km}$ radius from the location of the tuberculosis infected deer was used.

The sample area of northeastern lower Michigan was approximately $650 \mathrm{~km}^{2}$, bounded by 4 paved roads, and included portions of $\mathrm{Al}$ pena, Montmorency, Oscoda, and Alcona counties. This area is primarily privately owned and contains numerous unfenced parcels varying in size from 16 to 11,340 ha. Most of this land is used for hunting and other recreational pursuits. Land types fall into 5 broad categories and there is abundant water from streams and lakes. Conifer forest cover, including northernwhite cedar (Thuja occidentalis) and balsam fir (Abies balsamea), occurs on very poorly drained muck soils of ancient lake bottoms and comprises the winter range preferred by whitetailed deer. The other 4 types of land are used by deer throughout the remainder of the year. Ash (Fraxinus sp.), red maple (Acer rubram), and a variety of medium-sized shrubs are found on somewhat poorly drained sands of old glacial lakes. Jack pine (Pinus banksiana) and blueberry (Vaccinium sp.) are supported by deep, well-drained sands of glacial outwash channels. Moraines with well drained loamy sand soils support extensive stands of aspen (Populus sp.) and northern red oak (Quercus rubra). A final and minor component of this area is moderately well-drained sandy loams on which most of the land in agricultural production is found. Age class distribution of the forest types could generally be characterized as second or third growth deciduous and oldgrowth conifer.

Deer submitted for necropsy were aged by wildlife biologists utilizing tooth development and wear patterns (Severinghaus, 1949; Ryel et al., 1961). The heads and/or lungs were examined at the AHDL where the parotid, mandibular, medial and lateral retropharyngeal, bronchial and mediastinal lymph nodes and any visible lesions were collected (if available). A portion of each lymph node and any tissue with lesions was fixed in $10 \%$ neutral buffered formalin for histopathology, while the remainder was kept chilled prior to mycobacterial culture. Histopathology using routine hematoxylin and eosin (H\&E) (Prophet et al., 1992a) and acidfast (AF) staining (Prophet et al., 1992b) was done at the AHDL. Chilled portions of lymph nodes were shipped to both the MDCH and NVSL for mycobacterial isolation and identification.

Lymph nodes from deer suspected to be positive for bovine tuberculosis on gross (abscess or granulomatous lesion) or histologic examination were sent to $\mathrm{MDCH}$, and lymph nodes from all deer were sent to NVSL. Different methods were used by the two laboratories to process the tissues. At $\mathrm{MDCH}$, the lymph nodes were ground, digested, and concentrated (Kent and Kubica, 1985). Smears of the resulting material were stained and examined using a fluorescent acid-fast staining procedure (Kent and Kubica, 1985). Samples positive by the fluorescent staining method were examined using the Zeihl-Neelsen staining method (Kent and Kubica, 1985). Lowenstein Jensen media (Becton-Dickinson, Cockeysville, Maryland, USA), Middlebrook 7H11S media (Becton-Dickinson, Cockeysville, Maryland, USA), and a Bactec 12B broth vial (Becton-Dickinson, Sparks, Maryland, USA), were inoculated with the remaining material (Kent and Kubica, 1985). Media were examined for growth on a weekly basis for $8 \mathrm{wk}$. Isolates determined to be acid-fast by slide examination (Kent and Kubica, 1985) were tested by genetic probe (AccuProbes, Gen-Probe, San Diego, California) to determine whether they were members of the $M$. tuberculosis complex (Reisner et al., 1994). Complete species identification was performed using biochemical tests and high performance liquid chromatography to differentiate $M$. bovis from other members of the $M$. tuberculosis 


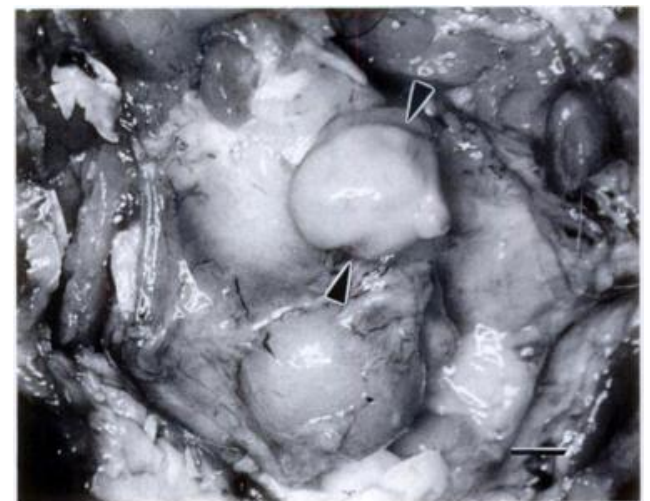

FIGURF 2. Right medial retropharyngeal lymph node from a white-tailed deer in Michigan infected with Mycobacterium bovis. The incised lymph node contains pale purulent material (arrowheads). Bar = $1 \mathrm{~cm}$.

complex and to speciate other mycobacteria (Kent and Kubica, 1985; Butler et al., 1991; Nolte and Metchock, 1995).

At NVSL, lymph nodes were trimmed of excess fat, macerated in phenol red nutrient broth (Becton-Dickinson, Cockeysville, Maryland, USA), decontaminated in $2 \% \mathrm{NaOH}$ for $10 \mathrm{~min}$, centrifuged for $20 \mathrm{~min}$, and the supernatant decanted (Payeur et al., 1993). Bactec 12 B (Middlebrook 7H12), modified Middlebrook 7H1l (Canadian formula) (Support Services Laboratory, NVSL, Ames, Iowa, USA), Stonebrink (Support Services Laboratory, NVSL, Ames, Iowa, USA), Middlebrook 7H10 (Becton-Dickinson, Cockeysville, Maryland, USA), Herrold Egg Yolk (Remel, Lenexa, Kansas), and Lowenstein Jensen media were inoculated with the sediment. The inoculated media were incubated at $37 \mathrm{C}$ for $12 \mathrm{wk}$ and examined for colony formation every week. All mycobacterial isolates were classified to species using standard growth and biochemical characteristics (Payeur et al., 199.3). Isolates were confirmed by genetic probe (AccuProbes) (Reisner et al., 1994; Stockman, 1994a) and gas liquid chromatography (Stockman, 1994b). Deer were classified as having bovine tuberculosis if $\boldsymbol{M}$. bovis was isolated from the tissue. Due to limited incubator space and economic consideration, not all deer were individually cultured at NVSL. In the absence of gross lesions, samples from 10 to 22 deer were pooled prior to culturing. The data were analyzed using Epi Info, Version 6.04a (Centers for Disease Control and Prevention, Atlanta, Georgia, USA; Dean et al., 1994).

\section{RESULTS}

Of the 354 hunter harvested deer examined, both the lungs and heads of 64 , only the heads of 257 , and only the lungs of 33 were available for examination. In three of these cases the whole carcass was presented to the MDNR. Gross lesions within the lungs and/or the pleural surfaces were reported by hunters in four of the deer; two additional deer had pulmonary lesions at gross necropsy. In these cases, numerous 5 to $10 \mathrm{~mm}$ diameter tan or yellow nodules were disseminated over the pleural surfaces and throughout the lung parenchyma (Fig. 1). In most cases, these lesions contained white to yellow purulent material although occasionally the lesions were caseogranulomas or had a gritty texture. Similar thoracic lesions were present in all six deer and one of these deer also exhibited enlarged mesenteric lymph nodes containing caseous material.

Gross lesions suggestive of tuberculosis were seen in 15 deer. Four deer had lesions in the lymph nodes of the head and their lungs/thoracic cavity, while 1 deer had lesions in the lungs and the lymph nodes of the head and mesentery. Gross lesions were seen in 9 cases in which only the head was submitted and in 1 case where only the lungs were submitted. Of the 14 animals with gross lesions present in the head, lesions were seen in only the medial retropharyngeal lymph nodes of 12 (86\%) animals, only the submandibular lymph nodes of $1(7 \%)$ animal, and in multiple cranial lymph nodes of $1(7 \%)$ animal. The medial retropharyngeal lymph nodes were bilaterally affected in 8 cases, and unilaterally affected in 5 cases. Most of these lymph nodes were grossly enlarged and contained white to yellow-green purulent material, although less frequently the lesions were pale caseogranulomas without frank pus (Fig. 2) or had a gritty texture.

Microscopic examination of hematoxylin and eosin stained tissue sections revealed lesions suggestive of bovine tuberculosis in 


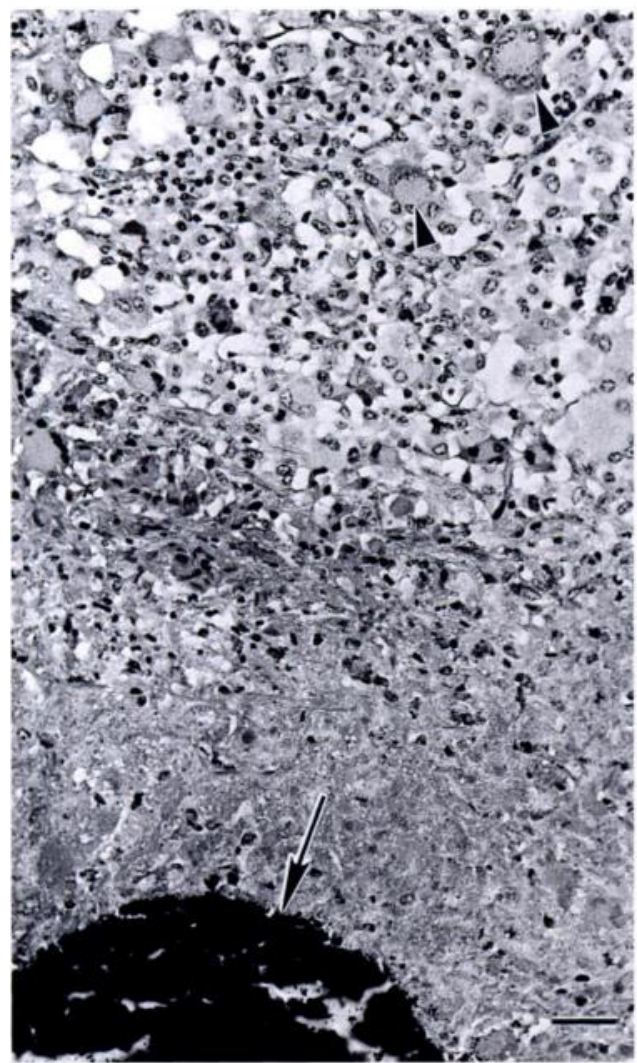

Figure 3. Photomicrograph of a caseogranuloma from a medial retropharyngeal lymph node from a white-tailed deer in Michigan infected with $\mathrm{Myco-}$ bacterium bovis. Centrally a dark zone of partially mineralized debris (arrow) is present. The peripheral zone contains large numbers of lymphocytes, macrophages, and multinucleated giant cells (arrowheads). $H \& E$ stain. Bar $=30 \mu \mathrm{m}$.

the 15 deer with gross lesions. Histologically, the lymph nodes contained variably sized zones of coagulative necrosis, which were surrounded by macrophages, lymphocytes, and variable numbers of Langhans type, multinucleated giant cells (Fig. 3). Many of the coagulative foci contained one or more areas of partial mineralization. In 4 other deer, in which gross lesions were not observed, lesions suggestive of bovine tuberculosis were found microscopically.

Acid-fast bacilli were observed in lesions from $84 \%$ (16/19) of the deer with microscopic lesions suggestive of bovine tuberculosis in the lymph nodes. Acid-fast ba-

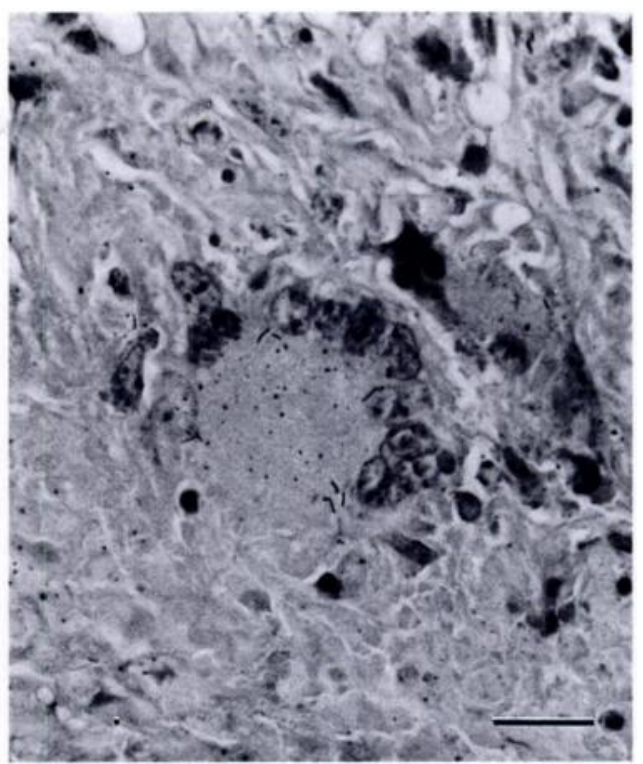

FIGURE 4. Photomicrograph of the same caseogranuloma as Figure 3. The cytoplasm of the multinucleated giant cell contains several acid-fast positive bacilli. Acid fast stain. Bar $=10 \mu \mathrm{m}$.

cilli were generally low in numbers requiring a diligent search at high magnification to find them. Bacilli were frequently located within histocytes and present extracellularly within the coagulum and less commonly within multinucleated giant cells (Fig. 4).

Acid-fast bacilli were isolated from 12 of $19(63 \%)$ deer with microscopic lesions compatible with tuberculosis. Genetic probe results indicated that isolates from all $12(100 \%)$ deer were in the M. tuberculosis complex (members include $\mathbf{M}$. tuberculosis, $M$. bovis, $M$. africanum, and $M$. microti). These 12 isolates were identified as $M$. bovis on standard growth and biochemical characteristics. Lymph nodes from 7 of 19 deer with microscopic lesions suggestive of bovine tuberculosis were not cultured individually at NVSL. Rather, lymph nodes of each of these 7 deer were pooled with lymph nodes from up to 20 other deer. Mycobacterium bovis was not isolated from the 7 resulting pooled samples. However, $\boldsymbol{M}$. bovis was cultured from another lymph node sample pooled from 12 deer without gross or microscopic le- 
sions. Although the cultures at the $\mathrm{MDCH}$ laboratory were incubated until there was significant growth or, if no growth was not$\mathrm{ed}$, for $8 \mathrm{wk}$ and those at the NVSL were incubated for $12 \mathrm{wk}$, there were no discrepancies noted among the deer samples cultured individually. In one case where NVSL pooled the sample and MDCH cultured the sample individually, only $\mathrm{MDCH}$ cultured $M$. bovis.

Nine of $198(5 \%)$ males and 3 of 132 (2\%) females submitted for examination were culture positive for $M$. bovis (excluding those animals of unknown sex, the culture positive pooled samples, and the 7 histologically positive but culture negative animals). The prevalence between males and females did not differ significantly (Kruskal-Wallis $\mathrm{H}=1.187, \mathrm{df}=2, P=$ 0.55 ). The overall apparent prevalence of bovine tuberculosis in hunter harvested free-ranging white-tailed deer in the surveillance area (as determined by mycobacterial culture) was $3.5 \pm 2.1 \%(12 / 342)$ and an additional $2.0 \pm 2.4 \%(7 / 342)$ were suspicious of bovine tuberculosis (had gross and/or histologic lesions). Ages of the tuberculosis positive deer ranged from 1.5 to $5.5 \mathrm{yr}$, with a mean of $3.2 \mathrm{yr}$ (median $3.5 \mathrm{yr}$ ) for females and $2.7 \mathrm{yr}$ (median 2.5 yr) for males.

\section{DISCUSSION}

There are few published reports of bovine tuberculosis in free-ranging cervids in the U.S.A., and none where the disease was maintained in the cervid population without infected livestock or bison serving as a reservoir. This is the first reported occurrence of bovine tuberculosis in freeranging cervids in North America where the disease is being maintained in the deer population without infected livestock involvement.

In our sample of heads, some thoracic viscera, and 3 whole carcasses, the medial retropharyngeal lymph nodes appear to be the site in white-tailed deer most frequently affected by bovine tuberculosis. This observation is in accordance with a previous report on bovine tuberculosis in cervids (Griffin and Buchanan, 1994). Although bilateral involvement was common, a significant number of individuals had unilateral involvement of these nodes. In our sample of hunter harvested deer, disseminated tuberculosis was rare. These results suggest that bilateral sampling of the medial retropharyngeal lymph nodes is critical in any survey program designed to detect bovine tuberculosis in cervids.

Gross lesions observed in our sample were most frequently pus-filled abscesses and occasionally caseogranulomas similar to previous reports (Clifton-Hadley, 1991; Griffin and Buchanan, 1994). Tuberculous lesions in deer are indistinguishable grossly from abscesses caused by Staphylococcus, Streptococcus, Actinobacillus or Actinomyces spp. Because the typical tuberculous lesions in cattle are caseogranulomas (Neill et al., 1994; Thoen and Bloom, 1995), diagnostic personnel must be aware of the tendency of deer to form abscesses, and microscopic evaluation and mycobacterial isolation are critical to prevent misdiagnosis.

Although, the NVSL and the MDCH used somewhat different techniques in culturing $M$. bovis, results from the 2 laboratories agreed in all cases except one. In this case, NVSL pooled a suspicious deer sample with 21 other deer samples and MDCH cultured the deer sample individually; only MDCH cultured $M$. bovis. In seven deer, gross lesions were not seen and these samples were pooled prior to the discovery of histologic lesions in the tissues from these animals. Mycobacterium bovis was not cultured from any of these pools. It appears that pooling of samples decreased the ability of the laboratories to culture the agent. While the specificity of mycobacterial culture is $100 \%$, the sensitivity of this test is influenced by the extent of tuberculosis in the animal and the quality of the sample submitted (Griffin and Buchan, 1994). Culture results from animals infected with tuberculosis may be negative due to small numbers of bacilli in 
tissues submitted or to destruction of $M$. bovis by the use of preservatives or decontaminates (O'Reilly, 1995). Because in many cases only the heads were examined and grossly normal deer were pooled prior to culturing, it is possible that some tuberculosis infected animals were culture negative.

The prevalence of tuberculosis noted in this report is the apparent prevalence in hunter-killed deer submitted to the MDNR for examination. This figure is influenced by which animals were harvested, whether the hunters chose to submit the carcass, and what portions of the carcass were submitted to the MDNR for examination. Also, the male:female sex ratio of the hunter-harvested deer (1.5:1) does not reflect that of the deer population in the affected area (estimated by the MDNR at 1:3). Although true prevalence remains difficult to quantify, the apparent prevalence is a useful measure in allowing us to monitor the spread of tuberculosis and the success of the disease eradication effort in the future. It is difficult to make a direct comparison between the situation in Michigan and other tuberculosis occurrences because there are no reports estimating the prevalence of tuberculosis in free-ranging white-tailed deer anywhere, or in any other free-ranging cervid species in North America. New Zealand, a country having wild and domestic animal reservoirs for tuberculosis, reported a $37 \%$ prevalence of tuberculosis in harvested freeranging red deer (Cervus elaphus scoticus) (Nugent and Lugton, 1995).

Tuberculosis caused by $M$. bovis is a zoonotic disease spread primarily by contact with infected animals and exacerbated by crowding and stress (Thoen and Himes, 1981). While there are numerous reports of tuberculosis in domestic livestock and captive cervid operations (Essey, 1995), wildlife in North America have never before been implicated as a reservoir for $\boldsymbol{M}$. bovis. It is thought that maintenance of $M$. bovis in Michigan white-tailed deer is re- lated to the focal density of this population and supplemental feeding.

Spring deer densities in the northeastern lower peninsula of Michigan have been maintained at 19 to 23 per $\mathrm{km}^{2}$ for many years. Focal concentrations of deer at feeding sites can result in much higher densities. At some feeding sites, several hundred deer have been observed. After a typical winter and in the absence of supplemental feeding, it is estimated that the deer density would decline to 9 to 10 per $\mathrm{km}^{2}$. While overall deer densities are moderately high for Michigan, it is the unnatural concentration of deer caused by supplemental feeding which is thought to play a major role in the transmission of tuberculosis between animals.

Supplemental winter feeding of deer has become common in northern Michigan as this practice is thought to decrease winter deaths due to starvation and increase the proportion of females producing and successfully supporting multiple births. Even non-hunters may engage in supplemental feeding for the pleasure of wildlife viewing and the psychological satisfaction received from the perception that wildlife have benefited from this practice. Supplemental feeding consists of placing a variety of foodstuffs including carrots, sugar beets, corn, and hay, in large piles and allowing wildlife free access to these products during winter (approximately 4 to 5 mo). This practice brings together a large number of deer for a prolonged period of time. Under these circumstances, inhalation of droplet nuclei or consumption of feed contaminated by coughing and exhalation becomes much more likely to occur than with a more free-ranging cervid population. Supplemental feeding has been implicated as contributing to the spread of tuberculosis in bison (Hadwen, 1942).

The presence of bovine tuberculosis in Michigan's white-tailed deer herd is a serious problem endangering deer, other wildlife, livestock, and humans. To address this unique situation, a multi-agency committee (MDNR, MDA, AHDL, MDCH, 
and the USDA) composed of individuals with diverse expertise and jurisdiction was formed. The proposed management strategy involves surveying wildlife populations, testing livestock, reducing supplemental feeding of deer, reducing the deer density in the area through legal hunting, and educating the public.

Surveillance for tuberculosis in the affected four-county area and in other parts of the state will continue. To further delineate the tuberculosis affected area of the four-counties and to monitor any spread of this disease, hunter-harvested deer surveys will be conducted on a yearly basis. Although bovine tuberculosis was not suspected elsewhere in Michigan, a statewide survey has been completed confirming that the remaining free-ranging deer population is free of $\boldsymbol{M}$. bovis. Because $\boldsymbol{M}$. bovis is known to affect a wide variety of species and wildlife have been implicated as a reservoir for tuberculosis in other countries (Nolan and Wilesmith, 1994; Patterson et al., 1995; Sauter and Morris, 1995), other wildlife in the affected fourcounty area, including opossum (Didelphis virginiana), raccoon (Procyon lotor), coyote (Canis latrans), red fox (Vulpes vulpes), bobcat (Felis rufus), and badger (Taxidea taxus), are being surveyed. Tuberculosis testing of domestic livestock (intradermal skin testing of all test eligible livestock) within an $8 \mathrm{~km}$ radius of each of the twelve $M$. bovis culture positive freeranging white-tailed deer has been completed with negative results. To better discern the extent and direction of whitetailed deer movements and subsequently the spread of tuberculosis, radio-collared deer will be monitored for at least 3 yrs.

The $M$. bovis infected area of Michigan may not be unique in having focal high deer densities and close contact between animals. There are other areas in Michigan, and perhaps elsewhere, with similar conditions. Wildlife and agricultural agencies should be aware of the potential danger created when cervid populations are managed at high densities and supplemen- tal feeding is allowed. Under these conditions, introduction of a pathogenic agent could lead to catastrophic consequences. Continued and expanded wildlife disease surveillance is needed in Michigan and throughout the United States.

\section{ACKNOWLEDGMENTS}

We thank MDNR, AHDL, MDA, MDCH, and USDA personnel who helped with the 1995 and 1996 deer surveys. Special thanks is extended to the deer hunters who participated in the surveys. This work was supported by the Federal Aid in Wildlife Restoration Act under Michigan Pittman-Robertson Project W-127-R. The assistance of $D$. Redmond and L. Neely in the preparation of the manuscript was greatly appreciated.

\section{LITERATURE CITED}

BELLI, L. B. 1962. Bovine tuberculosis in a whitetailed deer (Odocoileus virginianus). Canadian Veterinary Journal 3: 356-358.

Butler, W. R., K. C. Jost, JR., ANd J. O. Kilburn. 1991. Identification of mycobacteria by highperformance liquid chromatography. Journal of Clinical Microbiology 29: 2468-2472.

Clifton-Hadley, R. S., and J. W. Wilesmith. 1991. Tuberculosis in deer: A review. The Veterinary Record 129: 5-12.

Dean, A. G., J. A. Dean, D. Coulombier, K. A. BRENDEl, D. C. Smith, A. H. Burton, R. C. Dicker, K. Sullivan, R. F. Fagan, and T. G. ARNER. 1994. Epi Info, Version 6: A word processing, database, and statistics program for epidemiology on microcomputers. Centers for Disease Control and Prevention, Atlanta, Georgia, $601 \mathrm{pp}$.

ESSEY, M. A. 1995. Overview of bovine tuberculosis in captive cervidae. Proceedings of the U.S. Animal Health Association Meeting 99: 639.

- AND J. S. VANTIEM. 1995. Mycobacterium bovis infection in captive Cervidae: An eradication program. In Mycobacterium bovis infection in animals and humans, $\mathrm{C}$. O. Thoen and J. H. Steele (eds.). Iowa State University Press, Ames, Iowa, pp. 145-157.

Friend, M., E. T. Kroll, AND H. Graft. 1963. Tuberculosis in a wild white-tailed deer. New York Fish and Game Journal 10: 118-123.

FRYE, G. H. 1995. Bovine tuberculosis eradication: The program in the United States. In Mycobacterium bovis infection in animals and humans, $C$. $O$. Thoen and J. H. Steele (eds.). Iowa State University Press, Ames, Iowa, pp. 119-129.

Griffin, J. F. T., AND G. S. BuChan. 1994. Aetiolology, pathogenesis and diagnosis of Mycobacte- 
rium bovis in deer. Veterinary Microbiology 40: 193-205.

HaDWEN, S. 1942. Tuberculosis in buffalo. Journal of the American Veterinary Medical Association 100: 19-22.

KEAHEY, K. K. 1976. Report of laboratory examination for case \#I46139 (\#76-50). Veterinary Diagnostic Laboratories. Michigan State University, East Lansing, Michigan, 1 p.

KeNt, P. T., AND G. P. KubiCA. 1985. Public health mycobacteriology. A guide for the level III laboratory. U.S. Department of Health and Human Senices. Atlanta, Georgia, $202 \mathrm{pp}$.

LEviNe, P. P. 1934. A report on tuberculosis in wild deer (Odocoileus virginianus). The Cornell Veterinarian 24: 264-266.

Martin, S. W., A. H. MeEk, AND P. WilleberG, 1987. Sampling Methods. In Veterinary epidemiology principles and methods. Iowa State University Press, Ames, Iowa, pp. 22-47.

Neill, S. D., J. M. Pollock, D. B. Bryson, and J. HANNA. 1994. Pathogenesis of Mycobacterium bovis infection in cattle. Veterinary Microbiology, 40: $41-52$.

NOlan, A., AND J. W. WILEsmith. 1994. Tuberculosis in badgers (Meles meles). Veterinary Microbiology, 40: 179-191.

Nolte, F. S., AND B. MEtchock. 1995. Mycobacterium. In Manual of clinical microbiology. P. R. Murray, E. J. Baron, M. A. Pfaller, F. C. Tenover, and R. H. Yolken (eds.). American Society for Microbiology (ASM) Press, Washington, D.C., pp. $400-437$.

NugeNt, G. AND I. LugtoN. 1995. Prevalence of bovine tuberculosis in wild deer in the Hauhungaroa range, North Island, New Zealand. In Tuberculosis in wildlife and domestic animals. F. Griffin and G. De Lisle, Otago Conference Series 3. University of Otago Press, Dunedin, New Zealand, pp. 273-275.

O'ReILly, L. M. 1995. Tuberculin skin tests: Sensitivity and specificity. In Mycobacterium bovis infection in animals and humans. C. O. Thoen and J. H. Steele, (eds.). Iowa State University Press, Ames, Iowa, pp. 86-87.

Patterson, B. M., R. S. Morris, J. Weston, AND P. E. CowaN. 1995. Foraging and denning patterns of brushtail possums, and their possible relationship to contact with cattle and the transmission of bovine tuberculosis. New Zealand Veterinary Journal 43: 281-288.

Payeur, J. B., J. L. JarnagiN, J. G. Marquardt, L. A. SChaper, AND B. M. MARTIN. 1993. Laboratory Methods in Veterinary Mycobacteriology for the Isolation and Identification of Mycobacteria. National Veterinary Services Laboratories, Ames, Iowa, pp. 79-117.

Prophet, E. B., B. Mills, J. B. Arrington, and L. H. SOBIN (EDITORS). 1992a. In Laboratory methods in histotechnology. American Registry of Pathology, Washington, D.C., pp. 56-57.

1992b. In Laboratory methods in histotechnology. American Registry of Pathology, Washington, D.C., p. 219.

Reisner, B. S., A. M. Gatson, and G. L. WoOds. 1994. Use of gen-probe accuprobes to identify Mycobacterium avium complex, Mycobacterium tuberculosis complex, Mycobacterium kansasii and Mycobacterium gordonae directly from BACTEC TB broth cultures. Journal of Clinical Microbiology, 32: 2995-2998.

Rhyan, J., K. Aune, B. hood, R. Clarke, J. PayEUR, J. Jarnagin, AND L. STaCkhouse. 1995. Bovine tuberculosis in a free-ranging mule deer (Odocoileus hemionus) from Montana. Journal of Wildlife Diseases 31: 432-435.

, D. A. SaAri, E. S. Williams, M. W. Miller, A. J. DAVIS, AND A. J. WILSON. 1992. Gross and microscopic lesions of naturally occurring tuberculosis in a captive herd of wapiti (Cervus elaphus nelsoni) in Colorado. Journal of Veterinary Diagnostic Investigation 4: 428-433.

Ryel, L. A., L. D. FAY, AND R. C. VAN EtTeN. 1961. Validity of age determination in Michigan deer. Papers of the Michigan Academy of Science, Arts, and Letters 46: 289-316.

SAUTER, C. M., AND R. S. Morris. 1995. Behavioural studies on the potential for direct transmission of tuberculosis from feral ferrets (Mustela furo) and possums (Trichosurus vulpecula) to farm livestock. New Zealand Veterinary Journal 43: 294-300.

Sawa, T. R., C. O. Thoen, and W. T. Nagao. 1974. Mycobacterium bovis infection in wild axis deer in Hawaii. Journal of the American Veterinary Medicine Association 165: 998-999.

Severinghaus, C. W. 1949. Tooth development and wear as criteria of age in white-tailed deer. The Journal of Wildlife Management 13: 195-216.

Stockman, L. 1994a. DNA Probes for the identification of mycobacteria. In Clinical microbiology procedures handbook, Vol. 1, H. D. Isenberg (ed.). American Society for Microbiology, Washington, D.C., pp. 3.15.1-3.15.4.

1994b. Gas-liquid chromatography (microbial identification system) for the identification of mycobacteria. In Clinical microbiology procedures handbook, Vol. 1, H. D. Isenberg (ed.). American Society for Microbiology, Washington, D.C., pp. 3.14.1-3.14.5.

STUHT, J., AND L. D. FAY. 1975. Laboratory record for necropsy \#76-50, Wildlife Pathology Laboratory, East Lansing, Michigan, $7 \mathrm{pp}$.

STUMPFF, C. D. 1982. Epidemiologic study of an outbreak of bovine TB in confined elk herds. Proceedings of the U.S. Animal Health Association Meeting 86: 524-527.

Thoen, C. O., AND B. R. Bloom. 1995. Pathogen- 
esis of Mycobacterium bovis. In Mycobacterium bovis infection in animals and humans, C. $O$. Thoen and J. H. Steele, (eds.). Iowa State University Press, Ames, Iowa, pp. 3-14.
Infectious diseases of wild mammals, J. W. Davis, L. H. Karstad, and D. O. Trainer, (eds.). Iowa State University Press, Ames, Iowa, pp. 263-274.

Received for publication 24 October 1996. 